\title{
Intercellular Adhesion Molecule-1-deficient Mice Are Protected against Ischemic Renal Injury
}

\author{
K.J. Kelly, ${ }^{\star \S}$ Winfred W. Williams, Jr., ${ }^{\star \S}$ Robert B. Colvin, ${ }^{\ddagger \Uparrow}$ Shane M. Meehan, ${ }^{\ddagger \mathbb{1}}$ Timothy A. Springer, ${ }^{\uparrow \star \star}$ \\ José-Carlos Gutiérrez-Ramos, ${ }^{\| \star \star}$ and Joseph V. Bonventre ${ }^{\star \S}$ \\ $*$ Medical and ${ }^{\ddagger}$ Pathology Services, Massachusetts General Hospital, Departments of ${ }^{\S}$ Medicine, ${ }_{\text {Genetics, } \text {, and }}^{\llbracket}$ Pathology, \\ and **The Center for Blood Research, Harvard Medical School, Boston, Massachusetts 02114
}

\begin{abstract}
Studies in the rat have pointed to a role for intercellular adhesion molecule-1 (ICAM-1) in the pathogenesis of acute tubular necrosis. These studies used antibodies, which may have nonspecific effects. We report that renal ICAM-1 mRNA levels and systemic levels of the cytokines IL-1 and TNF- $\alpha$ increase $1 \mathrm{~h}$ after ischemia/reperfusion in the mouse. We sought direct proof for a critical role for ICAM-1 in the pathophysiology of ischemic renal failure using mutant mice genetically deficient in ICAM-1. ICAM-1 is undetectable in mutant mice in contrast with normal mice, in which ICAM-1 is prominent in the endothelium of the vasa recta. Mutant mice are protected from acute renal ischemic injury as judged by serum creatinine, renal histology, and animal survival. Renal leukocyte infiltration, quantitated morphologically and by measuring tissue myeloperoxidase, was markedly less in ICAM-1-deficient than control mice. To evaluate whether prevention of neutrophil infiltration could be responsible for the protection observed in the mutant mice, we treated normal mice with antineutrophil serum to reduce absolute neutrophil counts to $<100$ cells $/ \mathrm{mm}^{3}$. These neutrophil-depleted animals were protected against ischemic renal failure. Anti-ICAM-1 antibody protected normal mice against renal ischemic injury but did not provide additional protection to neutrophil-depleted animals. Thus, ICAM-1 is a key mediator of ischemic acute renal failure likely acting via potentiation of neutrophilendothelial interactions. (J. Clin. Invest. 1996. 97:10561063). Key words: cell adhesion molecules $\bullet$ kidney failure, acute - leukocytes - disease models, animal • endothelium, vascular
\end{abstract}

\section{Introduction}

Ischemia and reperfusion result in tissue injury in a number of organs, including heart, brain, kidney, and gastrointestinal tract, with important implications for patient morbidity and mortality. Acute renal failure is the most costly renal disease requiring hospitalization, and ischemic acute renal failure con-

Address correspondence to Joseph V. Bonventre, Massachusetts General Hospital East, 149-4002 13th Street, Charlestown, MA 02129-2060. Phone: 617-726-3770; FAX: 617-726-4356; E-mail: jbonvent@warren.harvard.edu

Received for publication 20 October 1995 and accepted in revised form 27 November 1995.

J. Clin. Invest.

(C) The American Society for Clinical Investigation, Inc.

0021-9738/96/02/1056/08 \$2.00

Volume 97, Number 4, February 1996, 1056-1063 tinues to be associated with a mortality rate of $\sim 50 \%$. The pathophysiological mechanisms leading to acute ischemic renal failure are not fully understood. There is no clinically accepted therapy that prevents cellular injury after ischemic injury to the kidney (1). We have proposed that the outer medullary vascular congestion that is seen in ischemic acute renal failure (2) may result, at least in part, from intercellular adhesion molecule (ICAM) ${ }^{1}$-1-mediated adhesion of leukocytes to the endothelium with obstruction of the venous vasa recta and/or leukocyte-mediated increases in endothelial permeability leading to erythrocyte aggregation and edema $(2,3)$. Interference with outer medullary blood flow would then result in sustained ischemia to the outer medulla, even after systemic blood pressure and total renal blood flow were returned to normal.

ICAM-1, CD54, an adhesion receptor of the immunoglobulin superfamily expressed on endothelial cells, is a counterreceptor of lymphocyte function-associated antigen (LFA)-1 (CD11a/CD18) and Mac-1 (CD11b/CD18) present on mast leukocytes. The CD54-CD11/CD18 interaction is an important determinant of leukocyte-endothelial cell adhesion (4). mAbs directed against ICAM-1 or LFA-1 are protective against both the functional impairment and histological changes of ischemic acute renal failure in the rat (5-7). Studies using ICAM-1 antibodies, however, cannot definitively establish the role of ICAM-1 in the pathophysiology of ischemic tissue dysfunction. Anti-ICAM-1 mAb may not block all ICAM-1-dependent interactions since ICAM-1 has multiple sites for integrin binding (4). Antibodies vary in their specificity. Blocking a particular epitope does not necessarily neutralize the functional activity of the protein to which the antibody is directed. Since not all of the functions of an adhesion molecule such as ICAM-1 are known, it is not possible to establish in vivo or in vitro the extent to which the antibody is neutralizing. In addition, antibodies trigger secondary cellular responses and have nonspecific immunological effects. Antibodies against adhesion molecules have been shown to mimic the effects of the natural ligands of the surface target molecule (8). Antibodies to neural cell adhesion molecule, for example, activate G-protein-coupled phospholipase $\mathrm{C}$ signaling pathways, increase cytosolic free calcium concentration, decrease intracellular $\mathrm{pH}$, and activate protein kinases (9). Antibodies to other adhesion molecules also have multiple effects on signaling and genetic responses in cells. For example, in cells treated with antibodies to $\beta 1$ integrins, there is increased tyrosine phosphorylation of a number of proteins (10). Antibodies to fibronectin receptors, which block adhesion of synovial fibroblasts to fibronectin, induce the expres-

1. Abbreviations used in this paper: ANS, antineutrophil serum; BUN, blood urea nitrogen; ICAM, intercellular adhesion molecule; MPO, myeloperoxidase. 


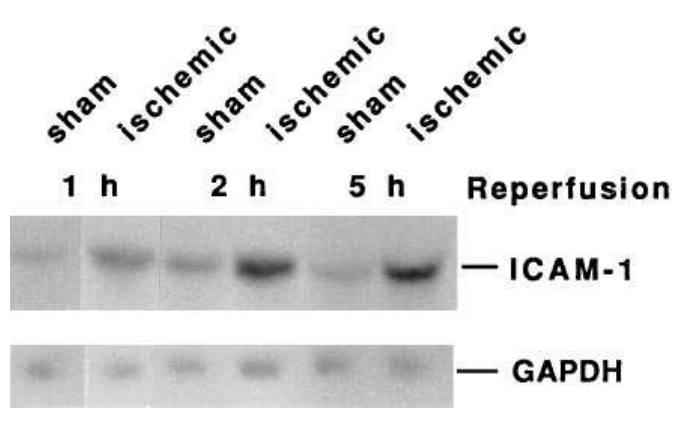

Figure 1. Effect of renal ischemia on ICAM-1 mRNA expression. Northern analysis demonstrates increased ICAM-1 mRNA expression in normal kidney tissue after renal ischemia and 1,2 , or $5 \mathrm{~h}$ reperfusion. Little ICAM-1 mRNA is detected after sham surgery. Hybridization with a full-length human GAPDH probe was used to demonstrate equal loading of lanes.

sion of genes encoding the metalloproteinases, collagenase and stromelysin (11). Furthermore, an antibody can induce a different set of signals and responses than the actual ligand does (11). It is possible that an antibody to ICAM-1 may trigger a response in endothelial cells that might confer protection against renal failure, but this response may be unrelated to the blocking function of the antibody. Thus, consequences of functional ablation of ICAM-1 are not necessarily predictable from prior studies using antibodies.
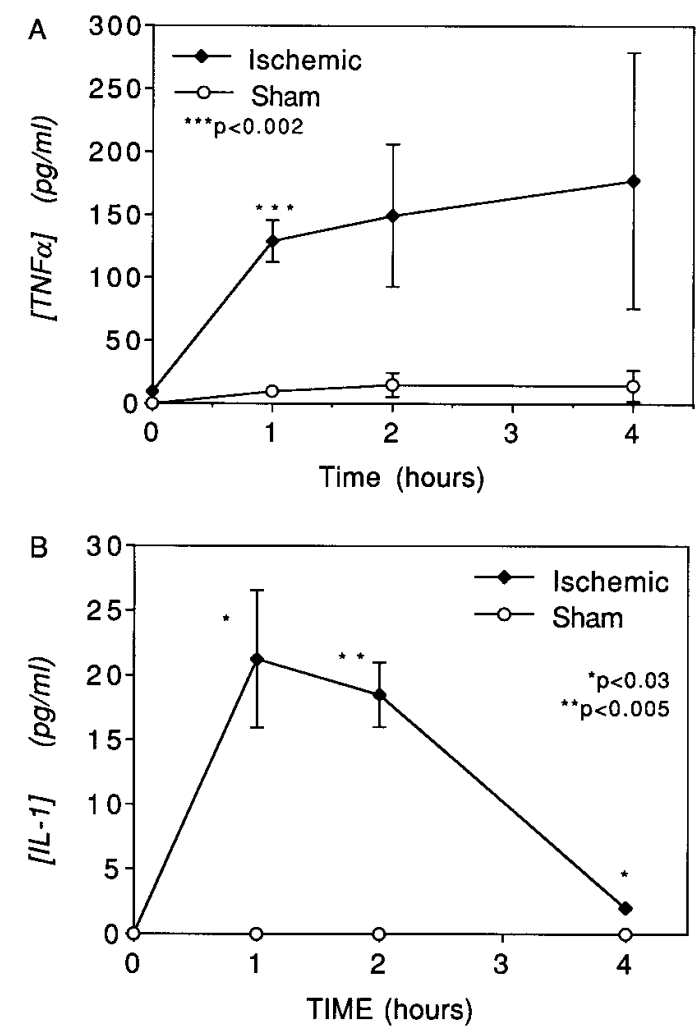

Figure 2. Effect of renal ischemia on TNF- $\alpha$ and IL-1 levels. Systemic TNF- $\alpha(A)$ and IL-1 $(B)$ levels were measured in normal mice $0,1,2$, and $4 \mathrm{~h}$ after renal ischemia or sham surgery. Data are expressed as means \pm SEM. Each point represents the mean of four values. $P$ values for comparisons between values in postischemic and sham animals are presented.
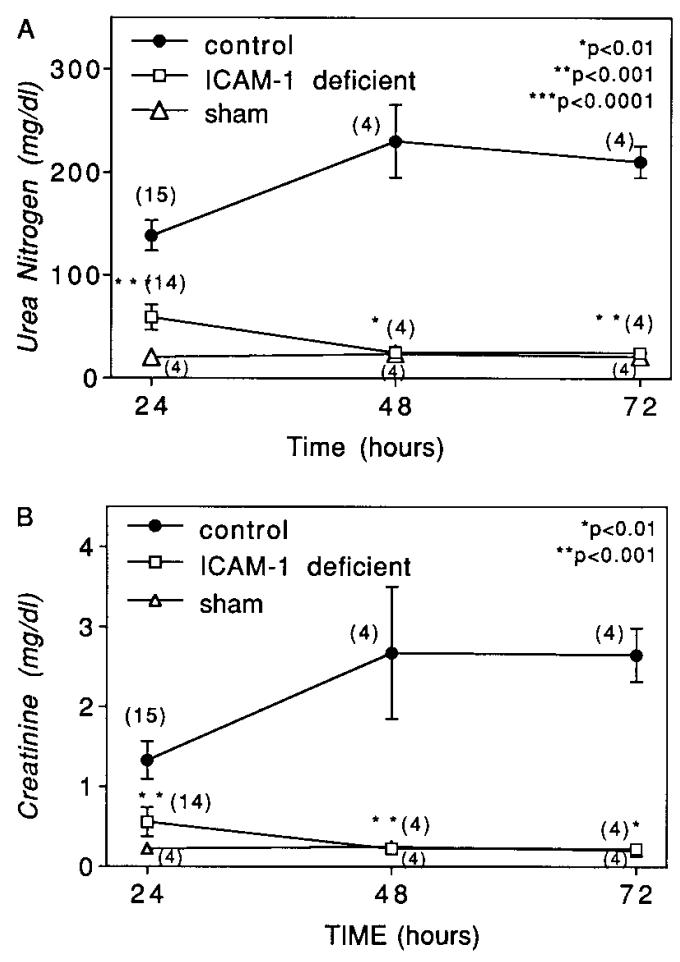

Figure 3. Effects of renal ischemia on renal function in normal and ICAM-1-deficient mice. Animals were subjected to bilateral renal pedicle clamping for $32 \mathrm{~min}$. Serum urea nitrogen $(A)$ and creatinine $(B)$ values were measured 24,48 , and $72 \mathrm{~h}$ after reperfusion or sham surgery. Data are expressed as means \pm 1 SEM. Numbers in parentheses represent the number of animals studied at each point. $P$ values for comparisons between values in ICAM-1-deficient and control mice are presented.

An alternative ablative approach that avoids these problems in interpretation of antibody studies involves the inactivation of the gene encoding ICAM-1. Genetic ablation of ICAM-1 has, in some cases, resulted in functional consequences that have been surprisingly different from those predicted from results with "blocking" antibodies (12). For example, the ICAM-1 "knockout" mouse demonstrated that ICAM-1 was not required for thymocyte differentiation, although prior studies, in thymic organ culture, indicated that blocking ICAM-1 with $\mathrm{mAb}$ during $\mathrm{T}$ cell differentiation resulted in accumulation of $\mathrm{CD}^{-} \mathrm{CD}^{-}$cells and delay in accumulation of $\mathrm{CD} 4^{+} \mathrm{CD} 8^{+}$cells (13).

The present studies were designed to seek definitive evidence for a role of ICAM- 1 in ischemic renal injury by determining the functional and histological consequences of bilateral renal ischemia in mice genetically deficient in ICAM-1 expression. We also sought to determine which leukocyte population mediates ischemic renal injury by examining the effects of neutrophil depletion on renal dysfunction that follows an ischemic insult.

\section{Methods}

ICAM-1-deficient mice. ICAM-1-deficient mice were produced (12) by homologous recombination of the ICAM-1 gene. The ICAM- 1 gene was interrupted in exon 4 by the neomycin resistance gene in embryonic stem cells. J1 embryonic stem cells heterozygous for the 
Table I. Mortality of ICAM-1-deficient and Control Animals

\begin{tabular}{lcc}
\hline & ICAM-1-deficient & Control \\
\hline Alive & 4 & 3 \\
Dead & 0 & 3 \\
& & \\
\hline
\end{tabular}

Only animals followed for $72 \mathrm{~h}$ after ischemia are included. A statistically significant $(P<0.05)$ difference in mortality was found between the ICAM-1-deficient and control mice.

disrupted ICAM-1 locus were used to produce chimeric mice, some of which showed transmission of the mutated ICAM-1 locus. Southern analysis of tail biopsy specimens was used to identify heterozygous mice, which were bred to produce homozygous ICAM-1-deficient mice. Wild-type littermates were used as controls. As previously reported (12), ICAM-1-deficient mice had no obvious abnormalities in tissue architecture. Activated thymocytes and spleen cells taken from these animals express no ICAM-1.

Ischemia protocols. ICAM-1-deficient and control mice weighing 20-40 $\mathrm{g}$ were anesthetized with intraperitoneal injection of sodium pentobarbital $(65 \mathrm{mg} / \mathrm{kg}) .1 \mathrm{ml}$ of $0.9 \% \mathrm{NaCl}$ at $37^{\circ} \mathrm{C}$ was also administered intraperitoneally. Core body temperature was maintained at $\sim 37^{\circ} \mathrm{C}$. Using a midline abdominal incision, renal arteries and veins were bilaterally occluded for $32 \mathrm{~min}$ with microaneurysm clamps, during which time the abdomen was closed. The time of ischemia was chosen to maximize reproducibility of renal functional impairment while minimizing animal mortality in these animals, who were not administered fluid intravenously. In one group of young mice pretreated with antineutrophil serum (ANS) (see below), the ischemic period was only $25 \mathrm{~min}$. After the renal pedicle clamps were removed, the kidneys were observed for an additional 5 min to document color change indicating reflow, and the incision was sutured. Sham surgery consisted of a surgical procedure that was identical except that microaneurysm clamps were not applied. Blood samples for blood urea nitrogen (BUN) and creatinine determination were obtained from the tail vein or via cardiac puncture at 24,48 , or $72 \mathrm{~h}$ after reperfusion. BUN and creatinine were measured by standard urease assay/conductivity and picric acid reactions, respectively. All experiments were blinded to the investigator performing the surgery until 2-3 d after the surgery, and to the pathologists scoring the sections until all the data were obtained.

Neutrophil depletion experiments. Approximately $16 \mathrm{~h}$ before ischemia, $150 \mu$ l of rabbit anti-mouse neutrophil serum (Intercell Technologies, Hopewell, NJ) or control antibody (anti-DPTA, the generous gift of Dr. Sy, Department of Pathology, Massachusetts General Hospital) was administered intraperitoneally to $129 / \mathrm{J}$ mice (The Jackson Laboratory, Bar Harbor, ME) weighing 20-40 g. The animals were subjected to bilateral renal ischemia as described above. Immediately after the microaneurysm clamps were applied, $200 \mu \mathrm{l}$ of antimouse ICAM-1 antibody derived from a hybridoma cell line $(14,15)$ obtained from American Type Culture Collection (Rockville, MD) or control antibody (anti-DPTA) or vehicle was injected via the internal jugular vein. In an additional set of experiments, mice weighing 20-25 g were administered ANS or control antibody as described above without the anti-ICAM-1 antibody or its control. These mice were then subjected to 25 min of bilateral ischemia $\sim 16 \mathrm{~h}$ after the
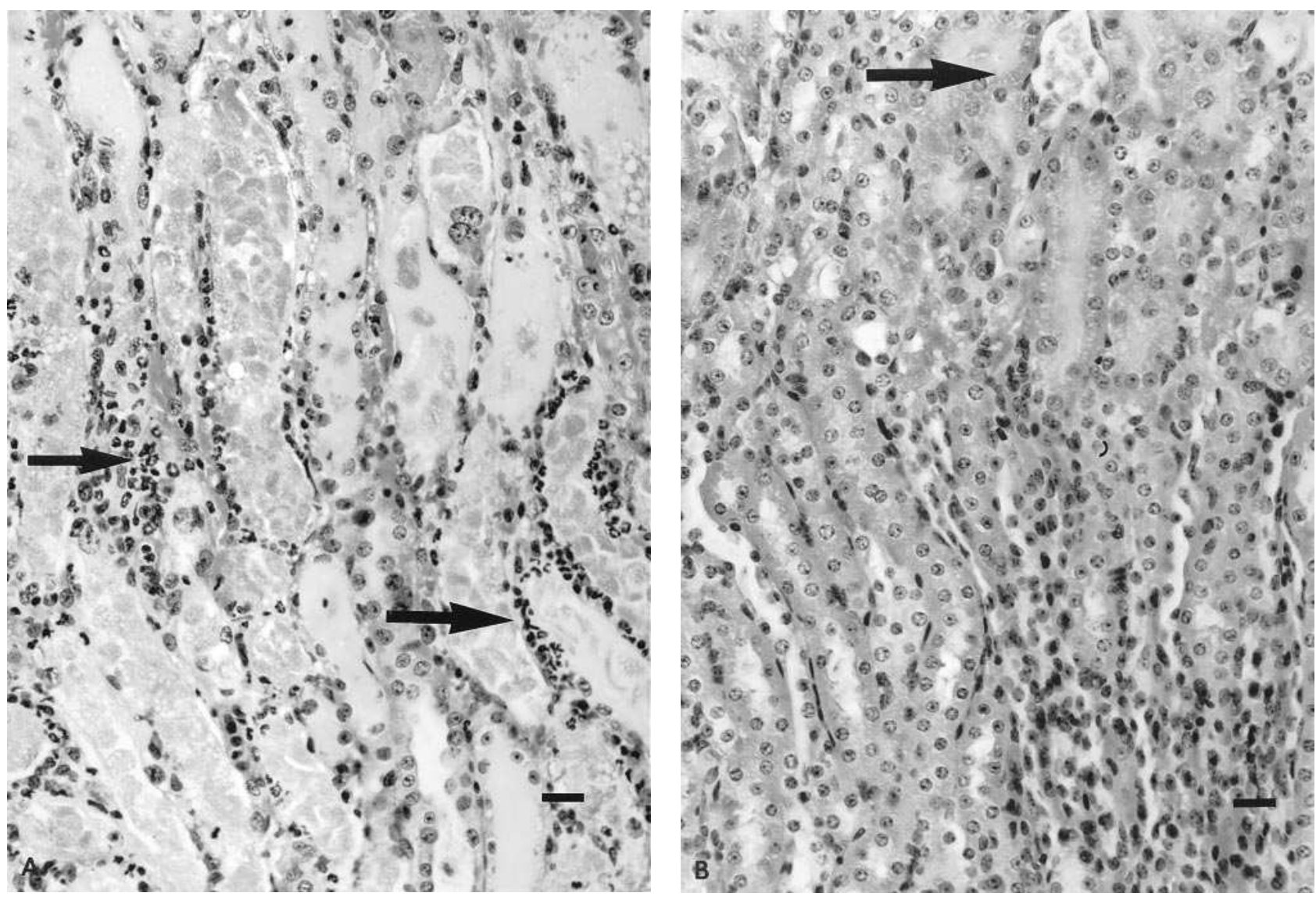

Figure 4. Effects of renal ischemia on histopathology in ICAM-1-deficient and control mice. Light microscopy of kidney outer medulla $48 \mathrm{~h}$ after $32 \mathrm{~min}$ of renal ischemia in a control mouse showing $(A)$ extensive tubular epithelial cell necrosis and a neutrophil infiltrates (arrows). A comparable section from an ICAM-1-deficient mouse after ischemia $(B)$ demonstrates trace amounts of tubular epithelial cell injury (arrow). Bar, $22 \mu \mathrm{m}$. 


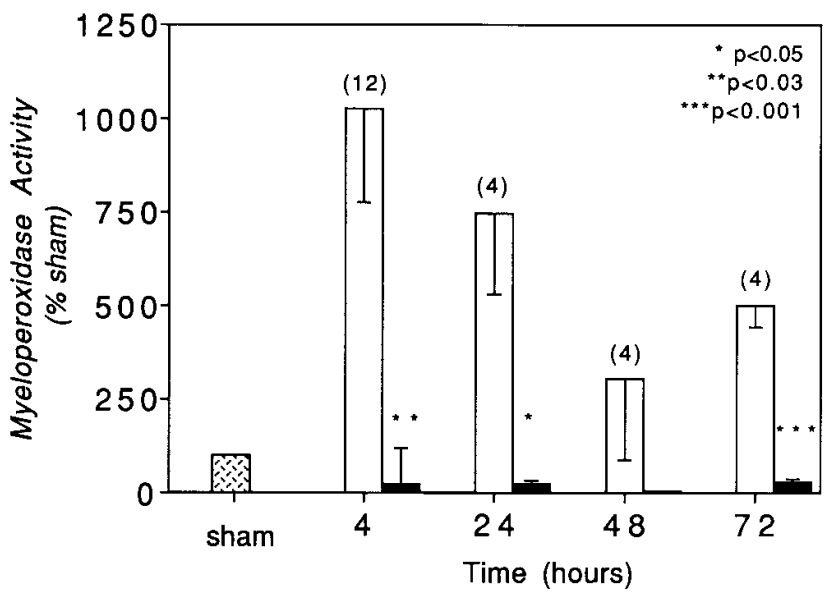

Figure 5. Effect of renal ischemia on MPO activity in ICAM-1-deficient mice. MPO activity was measured in kidney tissue $4,24,48$, or $72 \mathrm{~h}$ after reperfusion or sham surgery. MPO activity ( \pm 1 SEM) is presented as a percentage of activity at the same time after sham surgery in control animals. $P$ values are presented for comparison between control and ICAM-1-deficient mice.

ANS or control antibody. Blood for determination of absolute neutrophil counts was obtained by cardiac puncture from animals that had received ANS or control serum but were not subjected to renal ischemia. Neutrophil counts were determined manually on Wright'sstained smears. There were no statistically significant differences in the number of peripheral lymphocytes, monocytes, atypical lymphocytes, or eosinophils between the ANS and control groups. Blood for BUN and creatinine determination was obtained $24 \mathrm{~h}$ after ischemia as described above.

Light microscopy and immunohistochemistry. Kidney tissue was harvested at 24,48 , and $72 \mathrm{~h}$ after ischemia or sham surgery, fixed in a solution of $10 \%$ formaldehyde and $1.5 \%$ methanol, and paraffin embedded. $4-\mu \mathrm{m}$ sections were stained with hematoxylin and eosin. The percentage of tubules in the outer medulla that showed epithelial necrosis or had necrotic debris was estimated as follows: 0 , none; $1+$, $<10 \% ; 2+, 10-25 \% ; 3+, 26-75 \% ; 4+,>75 \%$. Infiltrating neutrophils were counted using an eyepiece graticule, at a magnification of 400 , and were quantitated as neutrophils per unit area $\left(0.0625 \mathrm{~mm}^{2}\right)$ of the outer medulla. We estimated the fractional area of the outer medulla containing any neutrophils by inspection of serial $\times 400$ fields. In those regions containing neutrophils, 5-15 fields were counted to derive a mean number of neutrophils per field. The number of neutrophils per unit area was then derived by multiplying the mean number of neutrophils per field with the fraction of area of the outer medulla containing these cells. All evaluations were made on coded sections without knowledge of the experimental group to which the mice belonged.

For immunohistochemistry, frozen kidney sections were incubated with anti-ICAM-1 (1:100) or ICAM-2 (1:500) followed by biotinylated secondary antibody, and finally by avidin-biotin-peroxidase (ABC method [5]). Staining of coded sections was graded as follows: 0 , none; $1+$, positive; $2+$, intensely positive.

Northern analysis. Total mRNA was prepared and blots were probed with ${ }^{32} \mathrm{P}$-labeled full-length mouse ICAM-1 cDNA (16) using standard techniques (17). Briefly, kidney tissue was homogenized in guanidine isothiocyanate and RNA isolated by centrifugation in a cesium chloride gradient. Hybridization was carried out in formamide at $42^{\circ} \mathrm{C}$, and the blots were washed in $2 \times \operatorname{SSPE}(150 \mathrm{mM} \mathrm{NaCl}, 10$ $\mathrm{mM} \mathrm{NaH}_{2} \mathrm{PO}_{4}, 1.0 \mathrm{mM}$ EDTA) at room temperature twice, $2 \times \mathrm{SSPE}$ at $65^{\circ} \mathrm{C}$, twice and then $0.5 \times$ SSPE twice at room temperature.

Myeloperoxidase (MPO) activity. MPO activity, used as an indicator of neutrophil infiltration, was measured (18) at 4, 24, 48, and
$72 \mathrm{~h}$ of reperfusion in coded kidney tissue from control and mutant mice and from sham-operated animals. Briefly, aliquots $(0.2 \mathrm{ml})$ of 40,000- $\mathrm{g}$ supernatants of kidney homogenates were added to $0.8 \mathrm{ml}$ of reaction buffer containing $50 \mathrm{mM}$ potassium phosphate, $\mathrm{pH} 6.0,0.2$ $\mathrm{mg} / \mathrm{ml} O$-dianisidine dihydrochloride, and $0.0006 \% \mathrm{H}_{2} \mathrm{O}_{2}$. Absorbance was determined at $460 \mathrm{~nm}$. MPO activity, normalized to protein content of the supernatant, was expressed as the percentage of measured activity in kidneys from mice subjected to sham operations.

TNF and IL-1 levels. Systemic levels of TNF- $\alpha$ and IL-1 were determined by ELISA as previously described (12). Blood was taken at $0,1,2$, and $4 \mathrm{~h}$ after release of the vascular clamps or sham surgery. TNF- $\alpha$ and IL- 1 concentrations were determined on serial dilutions of plasma samples, using ELISA (Endogen, Inc., Boston, MA) according to the procedure recommended by the supplier. Absorbance was determined at $450 \mathrm{~nm}$ with a spectrophotometer (Shimadzu Corp., Tokyo, Japan), and values were calibrated using a standard curve.

Statistics. Means of BUN and creatinine values, absolute neutrophil counts, and MPO activity were compared using analysis of variance followed by unpaired $t$ tests. Mortality rates and pathology scores were compared using Fisher's exact test, and neutrophil counts were compared with $t$ tests with unequal variances (19). A $P<0.05$ was considered statistically significant.
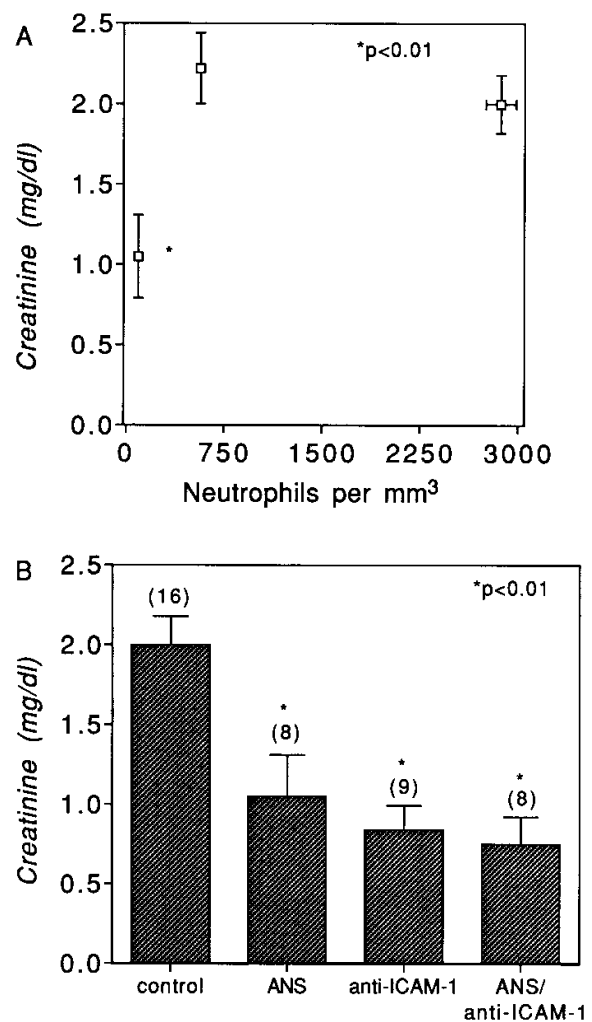

Figure 6. Effect of neutrophil depletion on renal dysfunction postischemia. $(A)$ The relationship between neutrophil count and renal function after administration of ANS or control serum to normal mice before renal ischemia. Mean serum creatinine ( \pm 1 SEM) $24 \mathrm{~h}$ after renal ischemia and mean absolute neutrophil count ( \pm 1 SEM) are presented. In each group, the leukocyte counts were determined in 4-8 animals and creatinine values in 6-16 animals. $(B)$ Effect of ANS and anti-ICAM-1 mAb on renal function after $32 \mathrm{~min}$ of ischemia and reperfusion in normal mice. Serum creatinine was measured $24 \mathrm{~h}$ after a 32 -min period of bilateral ischemia. Data are expressed as means \pm 1 SEM. Numbers in parentheses indicate the number of mice studied. $P$ values for comparison with control animals are shown. 
Table II. Number of Neutrophils/0.0625 $\mathrm{mm}^{2}$ and Extent of Tubular Necrosis of Outer Medulla after Ischemia Followed by Various Periods of Reperfusion

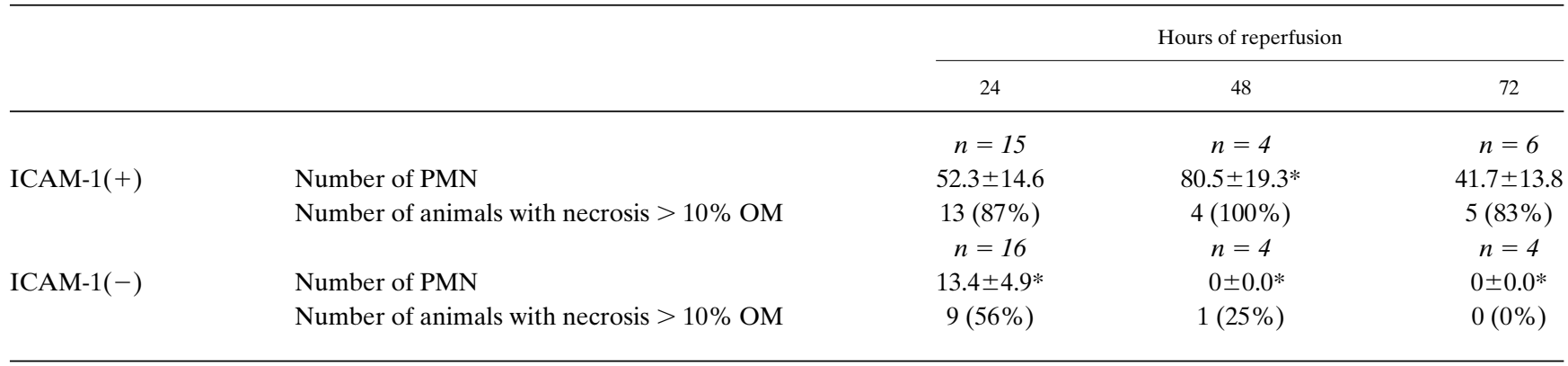

Number of polymorphonuclear neutrophils $(P M N)$ are means \pm 1 SE. Extent of tubular necrosis is given as number of animals with necrosis $>10 \%$ of outer medulla. $n$, number of animals in each group; $O M$, outer medulla; $I C A M-1(+)$, control mice; $I C A M-1(-)$, mice deficient in ICAM-1. ${ }^{*} P<0.05$ comparing numbers of neutrophils in ICAM-1(-) to ICAM-1(+) group. $P<0.01$ comparing extent of necrosis between ICAM-1(-) and ICAM-1 (+) groups for all time periods.

\section{Results}

In normal mice, after bilateral renal pedicle clamping for 32 min, and 1,2 , or $5 \mathrm{~h}$ of reperfusion in normal mice, kidney ICAM-1 mRNA levels were increased when compared with levels in kidneys from sham-operated animals (Fig. 1). Plasma concentrations of TNF- $\alpha$ and IL-1, two cytokines known to enhance ICAM-1 expression (4) levels, were elevated at 1 and $2 \mathrm{~h}$ and TNF- $\alpha$ remained elevated at $4 \mathrm{~h}$ after renal ischemia (Fig. 2). At $1 \mathrm{~h}$ after ischemia, mean serum TNF- $\alpha$ levels were $129 \pm 17$ $\mathrm{pg} / \mathrm{ml}$ in sera from postischemic mice and $9.8 \pm 5.7 \mathrm{pg} / \mathrm{ml}$ in sera from animals after sham surgery $(n=4, P<0.002)$. IL-1 levels were $21.3 \pm 5.3 \mathrm{pg} / \mathrm{ml}$ in postischemic mice and undetectable in the sera from sham animals $(n=4, P<0.03)$.

Serum creatinine increased approximately sevenfold over baseline after bilateral renal ischemia and $24 \mathrm{~h}$ of reperfusion in control mice and increased to 12 -fold baseline by $48 \mathrm{~h}$ after ischemia. ICAM-1-deficient mice were protected from ischemic renal injury (Fig. 3). Comparable protection from ischemic injury was found in both male and female ICAM-1-deficient mice (data not shown). None of the ICAM-1-deficient mice followed for $72 \mathrm{~h}$ after ischemia $(n=4)$ died, whereas $50 \%$ of the control postischemic $(n=6)$ animals died $(P<0.05$, Fisher's exact test) (Table I). At 24, 48, and $72 \mathrm{~h}$ after ischemia, histologic sections of the kidneys of control mice had significantly more tubular epithelial necrosis in the outer medulla than ICAM-1-deficient mice $(P<0.01$ by Fisher's exact test) (Fig. 4 and Table II). Regenerative activity, as evidenced by tubular epithelial cell mitoses, were prominent in the controls at 48 and $72 \mathrm{~h}$ (Fig. 4). Controls had significantly more neutrophils in the outer medulla than the ICAM-1-deficient mice did at 24, 48, and $72 \mathrm{~h}$ (Table II). Consistent with the histological identification of greater neutrophil infiltration in the control mice, kidney MPO activity at 4, 24, and $72 \mathrm{~h}$ after reperfusion was markedly greater in control postischemic mice than in ICAM-1-deficient mice (Fig. 5). Generalized neutrophil activation is supported by our unpublished observations in the rat, in which kidney ischemia and reperfusion result in an increased amount of MPO activity in the heart (data not shown).

No ICAM-1 was detectable by immunohistochemistry in the kidney tissue from mutant mice before or after ischemia, in contrast with normal mice that constitutively express ICAM-1 in the vasa rectae, peritubular capillaries, arterial endothelium, and faintly in glomeruli. It is of interest that the vasa rectae of both normal and ICAM-1-deficient mice constitutively express ICAM-2 (data not shown). Staining for ICAM-2 was present in the glomeruli, peritubular capillaries, vasa rectae, and arterial endothelium in ICAM-1-deficient, control, and sham-treated groups. Thus, ICAM-2 appears to be less important than ICAM-1 in the pathophysiology of ischemic renal injury.

We hypothesized that the protection seen in the ICAM1-deficient mice is due to the diminished localization of endovascular neutrophils in the kidney because of the absence of
A

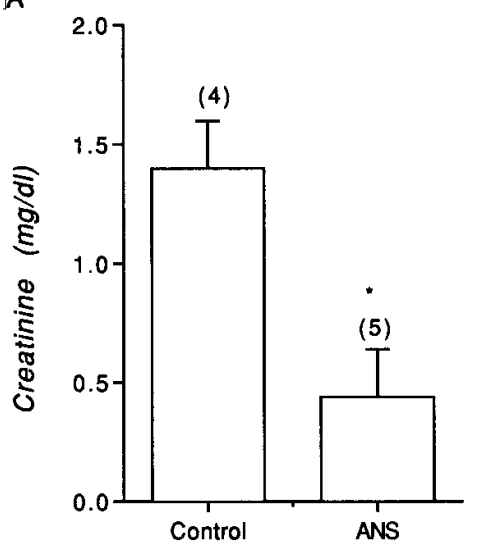

B

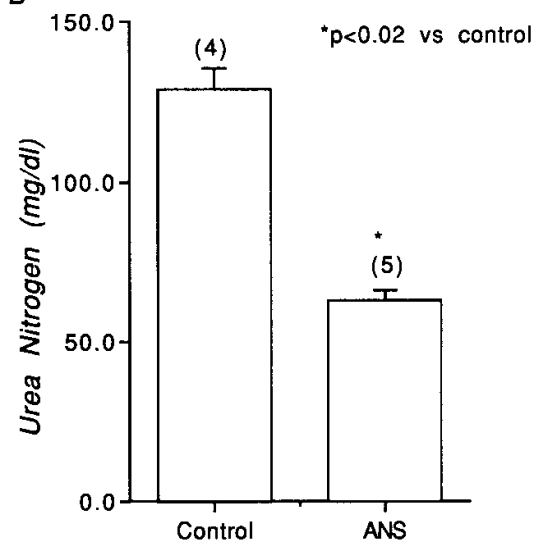

Figure 7. Effect of ANS mAb on renal function in young mice after $25 \mathrm{~min}$ of ischemia. Serum creatinine $(A)$ and blood urea nitrogen $(B)$ were determined $24 \mathrm{~h}$ after a 25-min period of ischemia in 20-25-g mice. Mean serum creatinine and urea nitrogen ( \pm 1 SEM) are presented. Numbers in parentheses represent the number of animals studied. $* P<0.02$ comparing ANS-treated mice with control mice. 
ICAM-1 expression on endothelial cells. To test this hypothesis, the effects of neutrophil depletion in normal mice on functional consequences of ischemia were assessed. Neutrophil depletion was produced by treatment with rabbit anti-mouse ANS. Furthermore, in order to compare the effects of neutrophil depletion with treatment with anti-ICAM-1 antibodies, one group of animals was administered anti-ICAM-1 mAb and another group of mice was treated with anti-ICAM-1 antibodies after neutrophil depletion. We found that the preparations of ANS lost efficacy to decrease neutrophil counts with time of storage. This provided us with an opportunity to evaluate how functional protection correlated with neutrophil depletion. As shown in Fig. $6 \mathrm{~A}$, there was a good correlation between peak creatinines at $24 \mathrm{~h}$ and absolute neutrophil counts at the time of ischemia. Protection against ischemic injury was seen only in those animal groups in which ANS treatment resulted in a reduction in the absolute neutrophil count to $<100$ cells $/ \mathrm{mm}^{3}$. As shown in Fig. $6 \mathrm{~B}$, the protection afforded by anti-ICAM-1 mAb alone was roughly equal to that afforded by severe neutrophil depletion. Anti-ICAM-1 mAb did not provide additional protection when administered to neutrophil-depleted animals. Protection is also seen with ANS treatment in younger mice (20-25 g) subjected to a shorter period (25 min) of ischemia (Fig. 7). The mean neutrophil count in these mice was $190 \pm 90$ cells $/ \mathrm{mm}^{3}$.

\section{Discussion}

These experiments demonstrate that ICAM-1-deficient mice are markedly protected from ischemic injury to the kidney. This protection is observed despite elevated baseline peripheral leukocyte counts. It has been previously reported $(12,20)$ that the mutant mice grow and reproduce normally with no increase in spontaneous infections (in a controlled environment). Lymphoid development is normal, but antigen-specific immune responses are decreased $(12,20)$. The ICAM-1-deficient mice are resistant to the lethal effect of high dose endotoxin, even though plasma concentrations of IL-1 and TNF- $\alpha$ are increased to levels seen in normal mice after endotoxin administration (12). The livers of mutant mice had much less infiltration of neutrophils in response to endotoxin when compared with wild-type mice despite the elevated peripheral neutrophil counts (10).

Our data suggest an important role for ICAM-1 and leukocyte-endothelial adhesion in the pathophysiology of ischemic renal failure. ICAM-1 is constitutively expressed in the vasa recta of normal animals. The elevated systemic $\mathrm{TNF}_{-} \alpha$ and IL-1 levels after ischemia and reperfusion provide a possible mechanism of upregulation of ICAM-1 in the postischemic tissue. These cytokines likely derive from the ischemic organ, as has been demonstrated in brain (21) and liver (22). To our knowledge, increases in systemic levels of IL-1 have not previously been demonstrated after renal ischemia and reperfusion. Sakr et al. have reported elevated TNF- $\alpha$ levels with ischemia and reperfusion in the rat kidney (23). IL-1 and TNF- $\alpha$ upregulate CD11b/CD18 expression on leukocytes, increase ICAM-1 expression on endothelial cells, and/or increase CD11/CD18 avidity for ICAM-1, thus increasing leukocyte endothelial adhesion and activation of leukocytes, augmenting local inflammatory mediators, and enhancing tissue damage (4). Administration of IL-1 to rats results in increased neutrophil infiltration of the kidney (24). Ischemia to the kidney re- sults in increased MPO levels in cardiac tissue (unpublished observations), suggesting that systemic factors such as TNF- $\alpha$ and IL-1 may enhance neutrophil adhesion to the endothelium of the heart and possibly other organs. This neutrophil adhesion in organs not directly involved with the insult may contribute to the development of multiple organ failure that is frequently seen with acute renal injury (1).

Given our previous localization of administered antiICAM-1 antibody to the vasa rectae of the outer medulla (5) and the inhibition of ischemia-induced increases in MPO activity in the kidneys of ICAM-1-deficient mice, these data are consistent with our hypothesis that ICAM-1 is critically involved in the interaction of leukocytes with the endothelium of the vasa recta. These leukocyte-endothelial interactions may contribute to residual obstruction of blood flow and prolonged local ischemia after the pedicle clamps are removed and may explain the medullary vascular congestion in the postischemic renal outer medulla $(2,3)$. We propose that the protection afforded by knockout of the ICAM-1 gene is due to prevention of leukocyte accumulation in the kidney with consequently less release of proteases, reactive oxygen species, and other toxic and vasoactive metabolites. Our data demonstrating quantitatively less neutrophil infiltration in the outer medulla of ICAM-1-deficient mice supports this hypothesis.

A role for neutrophils (PMNs) in ischemic injury to the kidney has been considered but never proven in vivo (25). It is theoretically possible that the protection against ischemic injury seen in the mutant mice and with anti-ICAM-1 treatment in the rat (5) may be unrelated to neutrophil-endothelial interactions. For example, ICAM-1 is a fibrinogen receptor (26), and one possible consequence of mutation of the ICAM-1 gene is decreased intravascular coagulation. Hellberg et al. (3) have suggested a role for erythrocytes in postischemic injury. To evaluate further the importance of the neutrophil, we tested whether neutrophil depletion could protect against ischemic injury in the normal mouse. Furthermore, to determine whether ICAM-1-dependent protection was neutrophil dependent, we investigated whether anti-ICAM-1 mAb treatment could provide additional protection over that observed with neutrophil depletion. The protection afforded the mice treated with ANS provides additional evidence for a role of neutrophils in ischemic acute renal failure. The fact that antiICAM-1 mAb did not confer additional protection in the neutrophil-depleted animals is consistent with, but does not prove, the hypothesis that protection from acute ischemic renal injury in ICAM-1-deficient mice or with anti-ICAM-1 mAb is neutrophil dependent.

Neutrophils accumulate in various organs after ischemia and reperfusion (27-29). Neutrophil depletion has been shown to protect rats against ischemic renal injury in some studies $(29,30)$ but not in others $(31,32)$. These studies varied with regard to the model of ischemia used, the measure of renal function, the age and gender of the animals, and, perhaps most importantly, the degree of neutropenia achieved. Hellberg et al. (29) reduced absolute neutrophil count to $60 \pm 10$ cells $/ \mathrm{mm}^{3}$ with ANS. In the neutrophil-depleted group inulin clearance was fourfold higher than in control animals. In the study by Klausner et al. (30), ANS was administered to rats $18 \mathrm{~h}$ before ischemia and resulted in a decrease in absolute neutrophil count to $125 \pm 56$ cells $/ \mathrm{mm}^{3}$. Mean creatinine in the neutrophildepleted group was $1.8 \pm 0.2 \mathrm{mg} / \mathrm{dl}$ vs $4.8 \pm 0.6 \mathrm{mg} / \mathrm{dl}$ in the control group $(P<0.05)$. In two other studies, protection was not 
observed in rats in which neutrophil counts had been reduced. In one case (31), however, the neutrophil counts (400-600 cells $/ \mathrm{mm}^{3}$ ) were significantly higher than levels attained in our studies in mice and the Hellberg et al. and Klausner et al. studies in rats. Thornton et al. (32) reduced absolute neutrophil counts in rats to a mean of $74 \pm 17$ cells $/ \mathrm{mm}^{3}$ with ANS and found no protection with ANS in a model of bilateral renal ischemia for 29 or $37 \mathrm{~min}$.

Several mechanisms may contribute to neutrophil-mediated reperfusion injury. Activated neutrophils can release cytokines, reactive oxygen species, proteases, elastases, MPO, and other enzymes. These substances upregulate adhesion receptors, are chemotactic, increase vascular permeability to other inflammatory cells, damage tissue directly (33), and impair endothelial function (33-35). Neutrophils increase injury to endothelial cells subjected to anoxia and reoxygenation (33). Endothelial layer damage results in a decreased vasodilatory response to hypoxia and acetylcholine (36), which may result in further ischemic injury. Activated neutrophils have increased adhesiveness and increased cytoplasmic stiffness and, along with aggregated platelets, can physically obstruct capillaries. Activated neutrophils produce vasoconstrictive arachidonic acid metabolites, which may potentiate vascular obstruction (37). Reperfusion of isolated perfused kidneys with activated neutrophils can accentuate the functional renal impairment observed with ischemia (38).

Our results may have significant implications for the treatment of ischemic acute renal failure and the preservation of renal allografts in humans. In a phase I trial, it has been shown that anti-ICAM-1 mAb can be administered safely to patients after renal transplantation (39). Our data suggest that agents designed to block leukocyte-endothelial interactions mediated via ICAM-1 may be therapeutically effective in the prevention and treatment of acute renal failure.

In summary, ICAM-1-deficient mice are protected against ischemia/reperfusion injury. Depletion of neutrophils in normal mice results in protection against ischemia-induced deficits in renal function. Administration of anti-ICAM-1 antibodies is protective in the mouse but does not confer protection beyond that observed with neutrophil depletion. These data suggest a critical role for leukocytes and adhesion molecules, in particular ICAM-1, in the pathophysiology of ischemic acute renal failure and may have important therapeutic implications for the treatment of acute renal failure in humans.

\section{Acknowledgments}

We thank T. DellaPelle and R. Kulbaki for technical assistance and Dr. A. Greene for assistance with data analysis and preparation of figures. This work was supported by the Joseph Shankman grant from the National Kidney Foundation of Massachusetts and Rhode Island and by National Institutes of Health (NIH) grants DK39773, NS 10828, T32DK07540, and HL 18646. Dr. Gutiérrez-Ramos is the Amy C. Potter fellow (NIH 10P1HL4867502).

\section{References}

1. Bonventre, J.V. 1993. Mechanisms of ischemic acute renal failure. Kidney Int. 43:1160-1178.

2. Mason, J., B. Joeris, J. Welsch, and W. Kriz. 1989. Vascular congestion in ischemic renal failure: the role of cell swelling. Miner. Electrolyte Metab. 15: 114-124.

3. Hellberg, P.O.A., O. Kallskog, and M. Wolgast. 1991. Red cell trapping and postischemic renal blood flow. Differences between the cortex, outer and inner medulla. Kidney Int. 40:625-631.

4. Springer, T.A. 1990. Adhesion receptors of the immune system. Nature (Lond.). 346:425-434.

5. Kelly, K.J., W.W. Williams, R.B. Colvin, and J.V. Bonventre. 1994. Antibody to intercellular adhesion molecule-1 protects the kidney against ischemic injury. Proc. Natl. Acad. Sci. USA. 91:812-816.

6. Rabb, H.A., C.C. Mendiola, J. Dietz, S.R. Saba, T.B. Issekutz, F. Abanilla, J.V. Bonventre, and G. Ramirez. 1994. Role of CD11a and CD11b in ischemic acute renal failure in rats. Am. J. Physiol. 267:F1052-F1058.

7. Rabb, H., C.C. Mendiola, S.R. Saba, J.R. Dietz, C.W. Smith, J.V. Bonventre, and G. Ramirez. 1994. Antibodies to ICAM-1 protect kidneys in severe ischemic reperfusion injury. Biochem. Biophys. Res. Commun. 211:67-73.

8. Schachner, M. 1993. The analysis of neural recognition molecules: benefits and vicissitudes of functional knock-outs using antibodies and gene ablation. Curr. Opin. Cell Biol. 5:786-790.

9. Schuch, U., M.J. Lohse, and M. Schachner. 1989. Neural cell adhesion molecules influence second messenger systems. Neuron. 3:13-20.

10. Kornberg, L.J., H.S. Earp, C.E. Turner, C. Prockop, and R.L. Juliano. 1991. Signal transduction of integrins: increased tyrosine phosphorylation caused by clustering of $\beta_{1}$ integrins. Proc. Natl. Acad. Sci. USA. 88:8392-8396.

11. Werb, Z., P.M. Tremble, O. Behrendtsen, E. Crowley, and C.H. Damsky. 1989. Signal transduction through the fibronectin receptor induces collagenase and stromelysin gene expression. J. Cell Biol. 109:877-889.

12. Xu, H., J.A. Gonzalo, Y. St. Pierre, I.R. Williams, T.S. Kupper, R.S. Cotran, T.A. Springer, and J.-C. Gutiérrez-Ramos. 1994. Leukocytosis and resistance to septic shock in intercellular adhesion molecule 1-deficient mice. $J$. Exp. Med. 180:95-109.

13. Fine, J.S., and A.M. Kruisbeek. 1991. The role of LFA-1/ICAM-1 interactions during murine T lymphocyte development. J. Immunol. 147:2852-2859.

14. Takei, F. 1985. Inhibition of mixed lymphocyte response by a rat monoclonal antibody to a novel murine lymphocyte activation antigen (MALA-2). $J$. Immunol. 134:1403-1407.

15. Horley, K.J., C. Carpentino, B. Baker, and F. Takei. 1989. Molecular cloning of murine intercellular adhesion molecule (ICAM-1). EMBO (Eur. Mol. Biol. Organ.) J. 8:2889-2896.

16. Ballantyne, C.M., W.E. O'Brien, and A.L. Beudet. 1989. Nucleotide sequence of the cDNA for murine intercellular adhesion molecule-1 (ICAM-1). Nucleic Acids Res. 17:5853.

17. Ouellette, A.J., R.A. Malt, V.P. Sukhatme, and J.V. Bonventre. 1990 Expression of two "immediate early" genes, Egr-1 and c-fos, in response to renal ischemia and during compensatory renal hypertrophy in mice. J. Clin. Invest. $85: 766-771$.

18. Bradley, P.P., D.A. Priebat, R.D. Christensen, and G. Rothstein. 1982. Measurement of cutaneous inflammation: estimation of neutrophil content with an enzyme marker. J. Invest. Dermatol. 78:206-209.

19. Ingelfinger, J.A., F. Mosteller, L.A. Thibodeau, and J.H. Ware. 1989. Biostatistics in Clinical Medicine. Macmillan Publishing Co., New York. 316 pp.

20. Sligh, J.E., C.M. Ballantyne, S.S. Rish, H.K. Hawkins, C.W. Smith, A Bradley, and A.L. Beaudet. 1993. Inflammatory and immune responses are impaired in mice deficient in intercellular adhesion molecule 1. Proc. Natl. Acad. Sci. USA. 90:8529-8533.

21. Minami, M., Y. Kuraishi, K. Yabuuchi, A. Yamazaki, and M. Satoh. 1992. Induction of interleukin-1 $\beta$ mRNA in rat brain after transient forebrain ischemia. J. Neurochem. 58:390-392.

22. Coletti, L.M., D.G. Remick, G.D. Burtch, S.L. Kunkel, R.M. Strieter, and D.A. Campbell. 1990. Role of tumor necrosis factor- $\alpha$ in the pathophysiologic alterations after hepatic ischemia/reperfusion injury in the rat. J. Clin. Invest. 85:1936-1943.

23. Sakr, M., G. Zetti, C. McClain, J. Gavaler, M. Nalesnik, S. Todo, T. Starzl, and D. Van Thiel. 1992. The protective effect of FK506 pretreatment against renal ischemia/reperfusion injury in rats. Transplantation (Baltimore). 53:987-991.

24. Guidot, D.M., S.L. Linas, M.J. Repine, P.F. Stanley, H.S. Fisher, and J.E. Repine. 1994. Interleukin-1 treatment increases neutrophils but not antioxidant enzyme activity or resistance to ischemia-reperfusion injury in rat kidneys. Inflammation. 18:537-545.

25. Linas, S.L., D. Whittenburg, P.E. Parsons, and J.E. Repine. 1992. Mild renal ischemia activates primed neutrophils to cause acute renal failure. Kidney Int. 42:610-616.

26. Languino, L.R., J. Plescia, A. Duperray, A.A. Brian, E.F. Plow, J.E. Geltosky, and D.C. Altieri. 1993. Fibrinogen mediates leukocyte adhesion to vascular endothelium through an ICAM-1 independent pathway. Cell. 73:14231434.

27. Granger, D.N., and R.J. Korthuis. 1995. Physiologic mechanisms of postischemic tissue injury. Annu. Rev. Physiol. 57:311-332.

28. Hallenbeck, J.M., A.J. Dutka, T. Tanishima, P.M. Kochanek, K.K. Kumaroo, C.B. Thompson, T.P. Obrenovitch, and T.J. Contreras. 1986. Polymorphonuclear leukocyte accumulation in brain regions with low blood flow during the early postischemic period. Stroke. 17:246-253.

29. Hellberg, P.O.A., O.T. Kallskog, G. Ojteg, and M. Wolgast. 1990. Peritubular capillary permeability and intravascular RBC aggregation after isch- 
emia: effects of neutrophils. Am. J. Physiol. 258:F1018-F1025.

30. Klausner, J.M., I.S. Paterson, G. Goldman, L. Kobzik, C. Rodzen, R. Lawrence, C.R. Valeri, D. Shepro, and H.B. Hechtman. 1989. Postischemic renal injury is mediated by neutrophils and leukotrienes. Am. J. Physiol. 256: F794-F802.

31. Paller, M.S. 1989. Effect of neutrophil depletion on ischemic renal injury in the rat. J. Lab. Clin. Med. 113:379-386.

32. Thornton, M., R. Winn, C. Alpers, and R. Zager. 1989. An evaluation of the neutrophil as a mediator of in vivo renal ischemia-reperfusion injury. Am. J. Pathol. 135:509-515.

33. Inauen, W., D.N. Granger, C.J. Meininger, M.E. Schelling, H.J. Granger, and P.R. Kvietys. 1990. An in vitro model of ischemia/reperfusioninduced microvascular injury. Am. J. Physiol. 259:G134-G139.

34. Lucchesi, B.R. 1990. Neutrophil-derived oxygen radicals in myocardial reperfusion injury. In Clinical Ischemic Syndromes. G.B. Zelenock, editor. Mosby, St. Louis, MO. 257-275.

35. Lefer, A.M., P.S. Tsao, D.J. Lefer, and X.-L. Ma. 1991. Role of endothe- lial dysfunction in the pathogenesis of reperfusion injury after myocardial ischemia. FASEB J. 5:2029-2034.

36. Malis, C.D., A. Leaf, G.S. Varadarajan, J.B. Newell, P.C. Weber, T. Force, and J.V. Bonventre. 1991. Effects of dietary $\omega 3$ fatty acids on vascular contractility in preanoxic and postanoxic aortic rings. Circulation. 84:13931401.

37. Forman, M.B., R. Virmani, and D.W. Puett. 1990. Mechanisms and therapy of myocardial reperfusion injury. Circulation. 81:IV69-IV78.

38. Linas, S.L., P.F. Shanley, D. Whittenburg, E. Berger, and J.E. Repine. 1988. Neutrophils accentuate ischemia-reperfusion injury in isolated perfused rat kidneys. Am. J. Physiol. 255:F728-F735.

39. Haug, C.E., R.B. Colvin, F.L. Delmonico, H. Auchincloss, N. TolkoffRubin, F.I. Preffer, R. Rothlein, S. Norris, L. Scharschmidt, and A.B. Cosimi. 1993. Phase I trial of immunosuppression with anti-ICAM-1 (CD54) mAb in renal allograft recipients. Transplantation (Baltimore). 55:766-773. 